

\section{Heinz First to Routinely Catheterize Carotid and Vertebral Arteries in America}

$\mathrm{T}$ he 1967 article of Amundsen et al, "Cerebral Angiography via the Femoral Artery with Particular Reference to Cerebrovascular Disease," was chosen by the American Journal of Neuroradiology (AJNR) as the "Best Paper" in neuroradiology in 2003. Heinz and associates developed the technique and routinely used it at Emory University in the United States in 1964, 3 full years earlier than its publication date.

There is a tendency to take our basic investigative tools in neuroradiology for granted. These include transfemoral cerebral angiography. Remember Egaz Moniz's original experience in which several of his first 9 patients died in $1927 !^{2}$ Percutaneous direct carotid puncture followed Moniz's original work, and this procedure persisted until 1964. In direct carotid puncture, the tip of the needle frequently created a posterior carotid wall "flap" when the tip was withdrawn to the midstream to obtain the best flow. This antegrade flow could elevate the posterior wall flap and obstruct blood flow to the brain. These flaps were not infrequently the site of local thrombotic deposition or cerebral embolism. We knew when we performed a carotid puncture that we were putting the patient at some small but definite risk. However, this technique was all we had to offer. Attempts at direct vertebral puncture were extremely difficult and the artery, when transfixed by the side-hole Sheldon-Swann needle, would frequently be narrowed by spasm. Failure to visualize the vertebrobasilar system by direct puncture led to the use of the right retrograde brachial arteriogram, but this study usually failed to sufficiently map the complete vertebrobasilar system.

When neuroradiologists attempted direct carotid puncture in infants and children in the early 1960s, we encountered many technical failures, most of which were secondary to the small caliber of the artery and the associated spasm that followed. Some centers had to resort to surgical cut-down for access. However, in 1964, we found a way to access all of the cerebral arteries with 1 puncture, the transfemoral cerebral angiogram (TFCA). We no longer had to puncture each carotid and vertebral artery individually in the neck.

Both Per Amundsen of Oslo, Norway, and the Emory University neuroradiology group in Atlanta, under my direction, began

http://dx.doi.org/10.3174/ajnr.A5429 to use TFCA for routine selective carotid and vertebral catheterization for all patients in 1964. However, Amundsen did not publish his TFCA article until $1967 .{ }^{1}$ Given neuroradiologists' common failure to image the vertebrobasilar arterial anatomy and, second, the great difficulty in puncturing and cannulating the carotid arteries in infants, it is not surprising that a solution would be found on each of 2 continents at roughly the same time. At the time, I did not think the technical change was sufficient to justify a scientific paper.

In 2001, the AJNR named a special panel to select the 10 neuroradiologic articles that would most represent the seminal underpinnings of our current clinical practice. Dr Amundsen's article on TFCA was published in a supplement to the journal Acta Neurologica Scandinavica in 1967 and was chosen as the most important of the 10 publications. ${ }^{3}$

Dr Amundsen's fellow Scandinavians, Eric Lindgren and Torgny Greitz, described the development of the Amundsen technique in 1995:

"Amundsen of Norway was the first routinely to catheterize and examine all cerebral vessels, carotid as well as vertebral arteries, a technique he had been using at the Ullevål Hospital in Norway since 1964. Hans Newton learned about the routine use of the femoral approach when he was in Sweden in 1966. He had earlier only occasionally used this method for carotid angiography. Newton was actually the first to perform a catheterization of the carotid artery from the femoral artery at the Karolinska Hospital. That was in 1966 when he came back from a week's visit in Oslo."3

For a description of the San Francisco neuroradiology technical procedures for the performance of cerebral angiography, I quote the description of John Mani, a member of the University of California, San Francisco (UCSF) team at the time Dr Newton left San Francisco for his sabbatical in 1965-1966 and who worked with Dr Amundsen ${ }^{3}$ :

"After one week, Per told me that he understood the UCSF approach. He was now going to introduce the Amundsen technique that he had been using in Norway for some time. Cerebral angiographic procedures were now to be done by the femoral technique, by using catheters and modified Seldinger technique."

During my training at Columbia, I chafed over the inadequacies of the retrograde brachial angiogram because of our usual failure to map the vertebrobasilar system adequately. Because I 
had experience with brachial venous angiography for the heart as a fourth-year medical student at the University of Pennsylvania, I was comfortable with vascular procedures. Later, I had a unique opportunity to learn the Seldinger technique for aortic and renal catheterization as a resident in radiology at the Philadelphia General Hospital. This took place in 1962, a year before my New York fellowship. Because I felt competent with arterial catheterization, I wanted very much to use it at Columbia for femoral-carotid angiography in 1962-1964, but I had to wait until I had my own program before I could put my experience to work. I was appointed as chief of "Special Procedures" at Emory University on July 1, 1964. In the next several months, our group initiated TFCA for all cerebral procedures in infants and adults. This included all vertebral angiograms. At the same time, we started a National Institutes of Health-sponsored neuroradiology fellowship program. Neuroradiology trainees included Dale Cooper MD, James Brylski MD, Peter Sones MD, and James Hoffman MD, as well as others. Dr Hoffman later became director of the program.

TFCA offered a second equally important advance, allowing catheterization of the tiny cerebral arteries in infants. This was as great as the gain in imaging the vertebrobasilar system in adults. Applying the newly developed TFCA approach at Emory using pediatric needles, 0.021-inch guidewires, and Kifa small-caliber catheters, which still had to be imported from Scandinavia, provided the answer. The femoral artery was much larger in caliber and easier to catheterize, farther away from the neck with its redundant soft tissue, and less painful and, finally, allowed easy selective catheterization of each of the cerebral arteries.

Drs Erik Lindgren and Torgny Greitz wrote an article on the evolution of vertebral angiography, "The Stockholm School of Neuroradiology." ${ }^{4}$ Radner was reported to be the first to catheterize the vertebral artery from the brachial artery approach. ${ }^{5}$ Lindgren was himself the first to catheterize the vertebral artery from the femoral artery in $19544^{4}$

"Amundsen of Norway was the first to catheterize and examine routinely all cerebral vessels, carotid as well as vertebral via the femoral route, a technique that he had been using at the Rikshospitalet in Oslo since 1964. Newton learned about this when Amundsen introduced this routine while the former was in Sweden in 1964." 2,4 According to Lindgren and Greitz and according to Rosenbaum et $\mathrm{al}^{3}{ }^{3}$ the sabbatical dates were 1965-1966, not 1964.

From these references, it appears that UCSF was mainly using existing standard angiographic techniques until Dr Newton returned from his 8-month sabbatical in 1965, after which UCSF began using cerebral catheterization for all cerebral angiography. By contrast, at Emory in 1964, we began to routinely use femoralcerebral catheterization for all cerebral angiography. Thus, Emory University was the first institution in America to use TFCA routinely for all of its cerebral angiography patients. It appears that Emory University and Amundsen's Rikshospitalet Hospital in Oslo each initiated the use of TFCA for routine cerebral angiography in 1964.
When I arrived at my new position at Emory in 1964, all procedures were performed by neurosurgery. Fortunately, our neurology colleagues realized that we might have something to offer and did refer a few patients. Our big opportunity came in the usual way: by showing our new colleagues that we could bring something new and better to patient diagnosis. It was the TFCA selective studies that gave access to the posterior circulation in adults and carotid and vertebral angiography in infants and children that made the difference. Within 1 year, neuroradiology performed all of the Emory studies. I was able to repeat this same process at Yale (1966), Pittsburgh (1969), and Duke (1978).

Why publish this information now? If the AJNR panelists came together and agreed that the Amundsen procedure was the most outstanding on the American list of contributions, then all the pertinent historical information about the presentation should be identified and included. My review of the 2001 AJNR report regarding TFCA suggests that there has been a historical omission. This omission could be corrected by adding 3 sentences to the AJNR panel report:

"While Amundsen published his classic article describing TFCA in 1967, routine utilization of TFCA for cerebral angiography was already instituted at Emory University in the United States in 1964, 3 years earlier. Routine use of TFCA in Atlanta took place in the same year that Amundsen began his routine use of TFCA in Oslo in 1964. While much of the emphasis on TFCA has focused on overcoming our inability to adequately image the vertebrobasilar circulation in adults, we call attention to the equally great additional contribution of TFCA to selective pediatric angiography of the carotid and vertebral arteries in infants and children."

My writing takes nothing away from the brilliant investigators Per Amundsen and Hans Newton (a personal friend). My goal is to simply fill in some of the details for the historical record while those of us who served in the period can accurately record it.

\section{REFERENCES}

1. Amundsen P, Dugstad G, Noyes W. Cerebral angiography via the femoral artery with particular reference to cerebrovascular disease. Acta Neurol Scand 1967;43:Suppl 31:115 Medline

2. Moniz E. L'encephalographie arterielle, son importance son la localisation des tumors des tumoeurs cerebrals. Rev Neurol (Paris) 1927;2:72-90

3. Rosenbaum AE, Eldevik OP, Mani JR, et al. In re: Amundsen P. Cerebral angiography via the femoral artery with particular reference to cerebrovascular disease-Acta Neurol Scand 1967; Suppl. 31:115. AJNR Am J Neuroradiol 2001;22:584-89 Medline

4. Lindgren E. Greitz T. The Stockholm School of Neuroradiology. AJNR Am J Neuroradiol 1995;16:351-60 Medline

5. Radner S. Vertebral angiography by catheterization; a new method employed in 221 cases. Acta Radiol Suppl 1951;87:1-134 Medline 